\title{
ESQUEMA DE UNA TEORÍA DEL AGENTE CENTRADA EN LA
} CREATIVIDAD

\author{
An outline of a creativity-centered theory of agency \\ Javier Luis Cristiano* \\ * Centro de Investigaciones y Estudios sobre Cultura y Sociedad (CIECS), CONICET \\ javier.cristiano.m@gmail.com
}

Palabras clave

Acción

Fantasía

Sentido Práctico

Narratividad

\section{Keywords}

Action

Fantasy

Practice Sense

Narrativity

\begin{abstract}
Resumen
Las diferentes tradiciones teóricas de la sociología han reconocido que la inventiva, la imaginación y la creatividad son rasgos inherentes a la acción humana. Sin embargo, han privilegiado en sus teorizaciones otros aspectos de la acción, como la racionalidad, el seguimiento de normas sociales, la espontaneidad de las prácticas cotidianas o las habilidades lingüísticas y comunicativas. La intención de este artículo es proponer un esquema amplio y flexible para el desarrollo de una concepción del agente centrada en la creatividad, cuyo interés para las ciencias sociales viene dado por el vínculo, intuitivamente obvio, pero extremadamente complejo, entre creatividad y emergencia de nuevas identidades y nuevas formas de organización social. El esquema parte de una concepción del agente como estratificación de niveles de consciencia y autoconocimiento, diferenciando un plano pulsional de la creatividad, un plano prereflexivo-práctico y un plano discursivo. En cada uno se identifican mecanismos específicos de la creatividad de la acción, para esbozar luego algunas hipótesis de articulación entre los tres y algunas líneas de investigación que podrían, a futuro, apuntalar la propuesta.
\end{abstract}

\begin{abstract}
Different theoretical traditions in sociology have readily admitted that inventiveness, imagination and creativity are distinctive features of human action. Yet these same traditions have focused in other elements of action, such as rationality, allegiance to social norms, spontaneity in everyday practices, or linguistic and communicative abilities. This article intends to offer a flexible framework for developing a creativity-centered conception of agency. From a social science perspective, this is relevant because of the intuitively obvious - yet undoubtedly complex - link between creativity and the emergence of new identities and forms of social organization. The framework builds upon a concept of agent as a stratification of selfconsciousness and self-control levels: a drive level of creativity, a prereflexive-practical level, and a discursive level. Specific mechanisms of creativity are identified in each level, in order to sketch a few hypotheses on the links between all three levels, and a set of future research lines that may strengthen this proposal.
\end{abstract}

Cristiano, J.L., 2016, "Esquema de una teoría del agente centrada en la creatividad", en Papeles del CEIC, vol. 2016/1, no 153, CEIC (Centro de Estudios sobre la Identidad Colectiva), Universidad del País Vasco, http://dx.doi.org/10.1387/pceic. 14284 
Aunque la capacidad "creativa" o "innovadora" del agente social ha sido reconocida por todas las tradiciones teóricas de la sociología, no contamos, hasta el momento, con una teoría sistemática al respecto. Entendemos por tal una descripción conceptual del agente que de cuenta de manera amplia, organizada y específica de esa capacidad y de su modo de funcionamiento, y que por ende pueda explicar, en el sentido más amplio de la palabra, numerosos y significativos aspectos de la experiencia social corriente. Lo que proponemos en este artículo es un esbozo elemental de esa teoría, cuyo ámbito natural de interlocución son las sociologías contemporáneas de la acción. Nuestro primer paso será aclarar el sentido concreto en que hablamos de "creatividad" (1) para formular después las premisas de la propuesta (2) y desarrollarla en sus trazos principales (3-6). Reservamos el cierre para una mirada global de la empresa que establece algunas orientaciones de su desarrollo futuro.

\section{UN CASO EMPÍRICO A MODO DE REFERENCIA}

Antes de comenzar conviene ofrecer una referencia empírica de "agencia creativa", a fin de orientar la lectura de lo que será un argumento predominantemente abstracto. A fines de 2001 se produjo en Argentina el derrumbe del sistema económico conocido como "convertibilidad", cobertura financiera de una década de políticas neoliberales que condujeron a una de las crisis más dramáticas de la historia económica, social y política del país. En medio del caos institucional del momento surgió un fenómeno que rápidamente convocó atenciones diversas por su carácter no convencional: el de las asambleas barriales. En las principales ciudades del país, vecinos con diferentes trayectorias e identidades, movidos por expectativas y urgencias de lo más variadas, dieron forma a una experiencia política inédita de la que surgieron numerosas formas alternativas de organización comunitaria, más allá del grado en que finalmente se plasmaron y de la deriva posterior que tuvieron las asambleas. Ana María Fernández, una de las primeras investigadoras en hacerse eco del fenómeno, sostuvo que la asamblea misma, en tanto práctica y organización, era novedosa: ni agrupamiento catártico, ni foro de discusión de ideas, ni movimiento de protesta social, ni movimiento insurreccional, "(...)tienen-dice Fernández-algo de cada cosa. Establecen nuevos modos de sociabilidad entre vecinos, que quiebran 
aislamientos, soledades y desamparos. También participan de diversas expresiones colectivas de protesta y subvierten en sus micro experiencias las formas hasta ahora obvias de la producción, el mercado, la propiedad, la cultura, la política (...) En tal sentido, se habilitan como espacios-tiempos que producen nuevos modos de existencia, que toman en sus propias manos lo que hay que hacer y abren nuevas dimensiones de lo político" (Fernández et al., 2006: 59).

\section{LA NOCIÓN DE CREATIVIDAD}

El La expresión "creatividad" tiene obviamente muchas acepciones, por lo que el primer paso necesario es precisarla. A efectos de nuestra propuesta vamos a definirla analíticamente como la capacidad de los agentes sociales de formular y ejecutar proyectos de acción nuevos, afirmación que requiere las siguientes consideraciones:

Hablamos primero de una capacidad, de una potencialidad. Y suponemos que se trata no de una disposición excepcional, propia de individuos especiales, sino de una latencia que caracteriza a todo agente. Con esto disipamos la asociación de creatividad con las cuestiones de la "genialidad" o la "inspiración" artística o científica, una de las matrices más comunes en que el tema ha sido discutido'. En segundo lugar asociamos la idea de creatividad a la de proyecto, haciendo nuestro un argumento de Alfred Schütz (1972: 87-92) según el cual la diferencia entre una acción con sentido y el mero comportamiento es precisamente la existencia de una figuración previa en la consciencia del acto que se va a ejecutar. Esa figuración puede ser plenamente consciente y lúcida, o en el otro extremo una anticipación fugaz e irreflexiva, pero siempre está presente si se trata de una acción con sentido. Para Schütz, este modo de concebir la acción tiene la doble ventaja de aclarar la idea de "sentido de la acción" y permitir establecer los límites de la acción (cuándo empieza y cuándo termina). Así, en referencia a alguno de los participantes en las asambleas, podríamos decir indistintamente que está buscando resolver sus necesidades urgentes, que está sumando apoyos a su moción o que está interviniendo

1 Esta en una de las matrices clásicas. A ella hay que agregar más recientemente una amplia bibliografía sobre la creatividad profesional, con fuerte predominio de psicología empírica y con marcado interés técnico instrumental. No entramos en discusión con esas orientaciones, aunque en última instancia una sociología de la creatividad debiera dar cuenta también de esos ámbitos. 
en la reorganización política de su comunidad, siendo lo que da sentido a su acción, y lo que nos permite establecer sus límites temporales y espaciales, el proyecto que le imputamos.

La creatividad implica por tanto la presencia de un tipo específico de proyecto, al que vamos a denominar nuevo. Con esto recogemos la connotación principal de "creatividad" en su uso corriente, que la asocia a las ideas de "innovación", "invención" y similares. Así, decimos que un acto es "creativo" en la medida en que pone en el mundo algo que no existía, lo que implica la presencia de un parámetro desde el cual establecerlo. Diremos que ese parámetro son las acciones precedentes, del propio actor o de otros actores, en un contexto de acción determinado. Así, para afirmar que la solución a un problema político es "creativa" debe tenerse en cuenta el modo en que el problema había sido abordado previamente, lo que implica tomar como referencia un estado específico del sistema de interacción del que se trata. Agregamos por último, también como aspecto de la novedad de un proyecto, que debe tratarse de una novedad en algún sentido relevante, pues, de nuevo con la guía del lenguaje ordinario, no diríamos que una acción es creativa por el sólo hecho de ser inédita o atípica, sino en la medida en que lo que introduce como novedad en el mundo sea significativo desde algún punto de vista valorativo.

La noción de creatividad está asociada a otra muy cercana que es la de imaginación. Como concepto de la filosofía y de distintas disciplinas humanísticas la imaginación tiene una amplia historia intelectual (Lapoujade, 1988; Warnock, 1981), que en el marco de este artículo no vamos a recoger. La usaremos en cambio en términos generales para referir en conjunto a las propiedades del agente que hacen a su condición de creativo. En otras palabras, afirmamos que los agentes son creativos porque tienen imaginación, refiriendo la imaginación al conglomerado de dimensiones agenciales que nos proponemos precisamente dilucidar. Nuestro análisis puede interpretarse también, en consecuencia, como una aclaración sociológica del concepto de imaginación.

Va de suyo que estas precisiones no agotan una noción tan esquiva como creatividad, pero establecen el acuerdo básico que necesitamos para la argumentación. 


\section{PLANTEAMIENTO GENERAL}

La elaboración de una teoría del agente puede seguir distintas metodologías entre las cuales una clásica, y la que aquí asumimos, es la formulación de un marco de referencia. Como es sabido, T. Parsons empleó esta expresión para referir un esquema abstracto en el que puedan situarse y hacerse interactuar aportes particulares de la sociología y de disciplinas conexas. Su "marco de referencia de la teoría de la acción" (Parsons, 1968: 78-87) ofrecía una gramática capaz de absorber y dar nuevo sentido a conceptos dispersos, resaltando a su vez puntos oscuros que indicaban áreas necesitadas de investigación. En nuestra opinión, la propuesta de Parsons puede retomarse a condición de descartar su conocida pretensión unificacionista. Quiere decir esto que establecer un marco de referencia es útil y legítimo, siempre y cuanto se reconozca que se trata de una construcción entre otras posibles, y que por ende no busca ni superar los elementos que emplea de otras teorías, ni unificarlos sin pérdida de significado respecto de sus marcos de origen, sino, simplemente, construir con ellos algo distinto.

En cuanto a su contenido, nuestro marco de referencia retoma una concepción también habitual del agente, a saber: la que pone el énfasis en sus grados de consciencia y autoconocimiento ${ }^{2}$. Partimos del supuesto de que un agente es una realidad psicosociobiológica en la que conviven y se superponen niveles diferenciables de conocimiento y control respecto de los mecanismos que mueven la acción. Distinguimos entonces y concretamente tres niveles básicos: el pulsional, el prereflexivo-práctico y el discursivo. Con este último nos referimos a la dimensión consciente del agente, en la que está en condiciones de explicitar y explicitarse a sí mismo, de manera discursiva, la naturaleza y

\footnotetext{
2 La inspiración básica de lo que sigue está tomada de A. Giddens y de su modelo "estratificado" del agente social (Giddens, 1995: 77-98). En el desarrollo del argumento se hará visible de todos modos importantes diferencias con ese modelo, que a nuestro juicio carece además de un desarrollo preciso y sistemático. La concepción del agente como una estratificación de niveles de consciencia está presente de todos modos en otros muchos autores, empezando por Freud y la tradición psicoanalítica. El acta fundacional de la sociología de la acción, que es la tipología de la acción propuesta por Max Weber, lo presupone en su gradación desde la racionalidad de fines hasta la "oscura semiconsciencia" (Weber, 1996: 18) de las acciones "tradicionales" y "afectivas". Numerosos debates sobre la descripción adecuada del agente social y de su vínculo con la "estructura" se centran directa o indirectamente en la cuestión de los niveles de consciencia y autodeterminación. Todo esto avala la opción por este modelo, pero en todo caso lo que valida su fortaleza es lo que logre construirse a partir de él.
} 
las razones de su acción. El nivel prereflexivo-práctico ubicamos al conjunto de saberes que el agente tiene y pone en juego en su acción, sin que esté en condiciones de hacerlos explícitos (como ocurre por ejemplo con las reglas sintácticas o pragmáticas). El nivel pulsional se refiere a la dimensión psíquica, que desde el psicoanálisis tiene al inconsciente como centro y que se refiere a las motivaciones profundas, y desconocidas por el agente, de la acción.

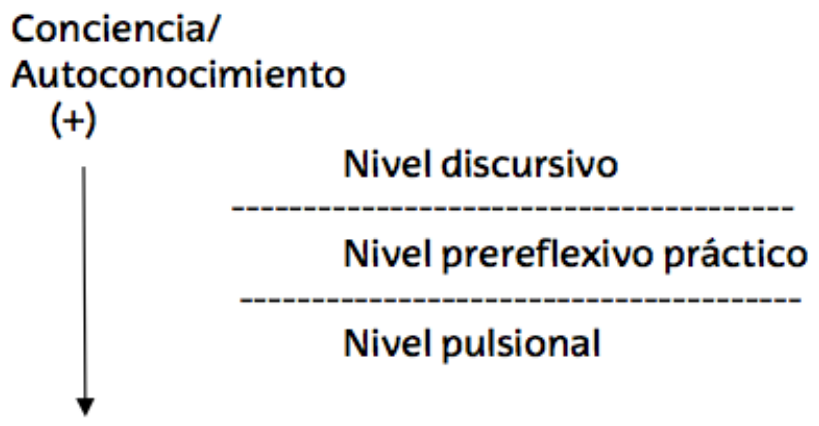

$(-)$

La gradación de consciencia/autonoconocimiento que indica el esquema no implica límites nítidos ni inmutables: es una cuestión de socialización, por ejemplo, el hecho de que el agente sea más o menos consciente de sus pulsiones, o sea más o menos reflexivo respecto de sus disposiciones prácticas. Lo importante es que estos niveles señalan planos diferentes de análisis, permitiendo asimilar conceptos y argumentos provenientes de perspectivas diversas. Conforman en este sentido un marco de referencia, pues por un lado abren la posibilidad de exploraciones tan amplias como se quiera y pragmáticamente se necesite y por otro, al situarlas en un esquema general, ofrece un medio para hacerlas interactuar.

Nuestra propuesta es entonces que, en cada uno de estos niveles, pueden identificarse aspectos concretos de la capacidad creativa del agente. Así,

- En el nivel pulsional nuestra hipótesis es que la economía del funcionamiento psíquico, tal como ha sido esclarecida en lo esencial por el psicoanálisis, da cuenta de dinámicas y mecanismos que explican procesos específicos asociados a la creatividad; 
- En el nivel prereflexivo-práctico suponemos que, durante el proceso de socialización, los agentes incorporan estructuras cognitivas y corporales que luego operan espontáneamente y que explican aspectos concretos de la capacidad de creación;

- En el nivel discursivo nuestra hipótesis es que, en la actividad de formular proyectos conscientes de acción, los agentes ponen en juego una modalidad específica de pensamiento, a saber, el pensamiento narrativo, cuya lógica y estructura organiza en este plano la actividad imaginativa y creativa.

El grueso de lo que sigue es la aclaración y plasmación de estas hipótesis que, como puede apreciarse, representan cada una un amplio campo de investigación. Llamamos "esquema" a nuestra propuesta precisamente porque se trata de un acercamiento selectivo a cada nivel, y porque tratamos de manera muy básica, en consecuencia, la cuestión de sus relaciones mutuas.

\section{El NIVEL PULSIONAL: FANTASíA, tOdAVÍA-NO-CONSCIENTE E IMAGINACION RADICAL}

El psicoanálisis es una gran cantera de recursos para abordar los temas de la creatividad y la imaginación ${ }^{3}$. Para nuestro acercamiento vamos a limitarnos a algunas de las ideas de Freud y a los aportes de dos autores que han radicalizado el papel de la creatividad en la economía psíquica, a saber: E. Bloch y C. Castoriadis. El hecho de que quede mucho fuera de consideración ${ }^{4}$ va, nos parece, en apoyo más que en desmedro de nuestra propuesta global.

De Freud rescatamos centralmente su reflexión sobre la fantasía y la actividad fantaseadora ${ }^{5}$, referida a un fenómeno - el de las fantasías o

\footnotetext{
3 Para una aproximación a los aportes del psicoanálisis a estos temas pueden verse Lapoujade (1986: 161 y ss.), Ungar (2001) y las entradas "fantasía" e "imaginario" en el Diccionario de Laplanche y Pontalis (1996).

4 Una consideración ampliada debería incluir como mínimo los desarrollos de Melanie Klein sobre las fantasías inconscientes, los de Susan Isaacs sobre la diferenciación entre fantasía diurna y fantasía inconsciente, los de Donald Winnicot sobre infancia, juego y espacio transicional, y la noción de "procesos terciarios" de André Green, ampliamente utilizada para analizar procesos creativos (por ejemplo por Fiorini, 2006).

5 "Fantasía" y "Fantasear" son las traducciones de Phantasie y Phantasiert, que en alemán remiten a "imaginación" en su sentido corriente (mundo imaginario, contenidos imaginarios, actividad imaginativa). Para la acepción filosófica más restringida se emplea habitualmente Einbildungskraft, categoría no empleada por Freud.
} 
"sueños diurnos"- del que extrae consecuencias para el análisis de una actividad: el arte y la expresión artística. Cuatro son las ideas que nos interesan puntualmente: (i) la fantasía es una actividad del pensamiento que, una vez instaurado el principio de realidad, permanece aferrada al principio de placer; (ii) el placer que produce la fantasía consiste en la satisfacción de deseos mediante la actividad representativa; (iii) el proceso del fantasear tiene una lógica específica, que une impresiones presentes con recuerdos y con futuros imaginarios; (iv) respecto del arte, Freud sostiene que deriva de las fantasías pero logra, por mecanismos concretos que analiza, trascender su carácter privado y apuntalarse en objetos que producen placer a otros.

En cuanto a lo primero (i) lo que se pone en juego es la dicotomía primaria del psicoanálisis entre principio de placer y principio de realidad. Según Freud el comienzo de la vida psíquica es la de un todo indiferenciado en el que rige el principio del placer, pues la psique acepta las representaciones que le propician bienestar y reprime las que no lo hacen. Con las primeras frustraciones empieza el largo proceso de instauración del principio de realidad, que no es más que el reconocimiento de la existencia de un mundo de objetos y de otros con el que debe contarse para la satisfacción de necesidades. Las consecuencias de este proceso son muchas (por ejemplo el refinamiento del apartado sensorial) pero una de ellas es la emergencia de la fantasía en su forma adulta, que consiste en la producción de representaciones libradas de la prueba de realidad y orientada exclusivamente a la producción de placer (Freud, 1980: 226-227). En el fantaseo diurno, por tanto, lo que hacemos es volver imaginariamente al origen indiferenciado y placentero, una idea que ha sido clave en varias corrientes posteriores del psicoanálisis ${ }^{6}$.

El placer que provoca la fantasía proviene concretamente de la satisfacción de deseos que la realidad no permite cumplir (ii). El sentido de este "no permite" es amplio-desde la imposibilidad objetiva hasta la inhibición moral-pero en todos los casos el sueño diurno es similar al nocturno: satisface pulsiones mediante representaciones "libres". La diferencia está en la intensidad de la censura y en la complejidad de la interpretación que requiere, pero en ambos el vínculo principal es entre representación y deseo.

6 Por ejemplo en la noción de "mónada psíquica" de Castoriadis (1998a). 
Freud aportó además un análisis del mecanismo psíquico que se desencadena en la producción de fantasías (iii). Puede resumirse en la idea de que, primero, una experiencia presente suscita la movilización de un deseo, que retrocede al pasado para recuperar las huellas mnémicas de experiencias anteriores de satisfacción; desde allí, y con ambos materiales, la psique elabora una situación hipotética futura en la que la satisfacción se produce nuevamente. "Pasado, presente y futuro-dice Freud-son como las cuentas de un collar engarzado por el deseo" (Freud, 1979: 130), y lo importante es que el contenido de las fantasías queda atado a la singularidad de la experiencia biográfica y de las situaciones específicas que la movilizan.

Finalmente, el arte proporciona una suerte de prototipo de práctica social en donde la fantasía, que tiene esencialmente un carácter privado, se vuelve objetividad y por ende intersubjetividad. Lo que sostiene Freud es que la actividad artística se apoya en el fantasear en tanto realidad psíquica, pero logra superar esa condición mediante dos mecanismos: la habilidad del artista para complejizar y encubrir el sueño diurno, modificándolo hasta hacerlo irreconocible; y su capacidad para producir placer a través de la forma, placer específicamente estético. Con eso el artista recorre un camino de retorno, pues aunque su fantasear se mantiene aferrado al placer, y por ende al deseo y a la pulsión, consigue poner en el mundo real algo que es significativo para otros.

Estas rápidas pinceladas ${ }^{7}$ dejan establecido lo que puede considerarse el núcleo del nivel pulsional de la creatividad, a saber, el que une la imaginación con el deseo y con el placer. Ponen también en claro sin embargo su parcialidad, si de lo que se trata es de comprender la creatividad como dimensión de la acción social. Pues, aunque el fantaseo diurno tenga su expresión en el arte, es claro que no es el arte su única manifestación, y aunque la fantasía tenga contacto con la acción, ese contacto no fue desarrollado por Freud-excepto en el caso del comportamiento patológico. En una obra mucho más politizada y también más próxima a los intereses de la sociología, Ernest Bloch (2004) realizó dos aportes concretos precisamente en esa dirección. En

7 No es esto obviamente todo lo que puede decirse del tema desde Freud. Las nociones de sublimación y de fantasías originarias integran el elenco de categorías que podrian incluirse y que dejamos momentáneamente de lado. Cfr. respectivamente Laplanche (1999); Laplanche y Pontalis (2008). 
primer lugar puso en discusión la tópica freudiana de consciente, preconsciente e inconsciente, afirmando que en ella, y en particular en sus dos elementos principales (el inconsciente y preconsciente), sólo parece haber lugar para lo reprimido y olvidado, lo "ya no consciente", y no para contenidos psíquicos nuevos. En otras palabras, lo que sostiene Bloch es que en la tópica freudiana ${ }^{8}$ no hay espacio para las representaciones que no repiten sino que anticipan algo que la consciencia todavía no ha vivido. Para eso propuso la noción de todavíano-consciente, un espacio tópico que, a diferencia del consciente, el inconsciente y el preconsciente, sería "el lugar psíquico del nacimiento de lo nuevo" (Bloch, 2004: 150).

Su segundo aporte se refiere a los sueños diurnos, interpretados ahora como manifestación del todavía-no-consciente. A diferencia de Freud, sostuvo que el sueño diurno y el nocturno tienen solo un parecido lejano, pues el primero puede producir contenidos que no tienen precedentes. El sueño nocturno retrocede a los fondos inconscientes y recoge de alli sus materiales; combina y deforma por mecanismos de defensa, pero no produce en esencia nada nuevo. El sueño diurno, en cambio, puede fabricar realidades inéditas, y por eso no se limita tampoco al fenómeno privado, autocensurado y ajeno a lo real que Freud tiene en mente: de los sueños diurnos surge también el proyecto, la voluntad de plasmar en la realidad lo que se ha "soñado despierto". Con ello se desliga también del imperio exclusivo del principio de placer y se enlaza con el principio de realidad.

Ambas ideas de Bloch vienen a complementar el esquema del psicoanálisis, resaltando el papel de la creatividad y subrayando el carácter agencialmente activo del vínculo deseo/fantasía. En una dirección distinta, y con un compromiso más fuerte con el proyecto freudiano en su conjunto, la obra de C. Castoriadis abre una vía distinta y de sumo interés para nuestro análisis. Su objeción a Freud es que puso todo el énfasis en la explicación de la vida anímica, lo que implica reducir su complejidad a una serie de variables que la convierten en un "aparato" científicamente dilucidable. Ello es correcto en un nivel de análisis pero deja fuera el carácter en última instancia indeterminado del flujo representativo que produce la psique. Tanto en los sueños

8 Es sabido que Freud propuso una segunda tópica referida al yo, el superyó y el ello. En principio nos parece que la objeción de Bloch es válida también para ella, pero el tema excede nuestro marco de análisis. 
como en las fantasías, en la vida consciente y mucho más en la inconsciente, el movimiento representativo de la psique tiene siempre un plus de indeterminación, que el psicoanálisis reconoce pero considera residual. Castoriadis propone el concepto de imaginación radical para describir precisamente ese carácter en última instancia indeterminado de la psique, que es la garantía de su capacidad de producir siempre novedad.

No es necesario para nuestros fines profundizar en los argumentos de Castoriadis en esta línea ${ }^{9}$; destacamos solamente la idea de que el flujo representativo de la psique no puede ser reducido a un esquema lógico conjuntista-identitario, que como tal desborda cualquier funcionalidad orgánica o psíquica, y que sea lo que sea el proceso de socialización, la psique conserva siempre un espacio de indeterminación en el que pone en movimiento la imaginación radical. La imaginación, con ese conjunto de ideas, deja de ser una actividad entre otras de la psique, para convertirse en lo propio y característico de su misma naturaleza.

Resumiendo, el nivel pulsional de la creatividad incluye por lo menos la estrecha conexión de la fantasía con el placer y con el deseo; la precisión del lugar tópico de la fantasía y la imaginación (para la que Bloch propuso la idea de todavía-no-consciente); la proyección de la fantasía diurna sobre los proyectos de acción realistas; la potencia creadora de la psique que emerge de su esencial indeterminación. En una teoría efectivamente sistemática del agente éstos y otros elementos deberían quedar integrados en un espacio conceptual común; tal como los planteamos alcanzan para dar cuenta de la riqueza del nivel pulsional de la creatividad y de la importancia de no desatenderlo.

\section{EL NIVEL PRE-REFLEXIVO PRÁCTICO: TIPIFICACIONES, MARCOS Y HABITUS}

Nuestro segundo nivel es mucho más familiar a la sociología, y de hecho varios de sus aportes más conocidos pueden situarse en él. Hemos seleccionado para darle contenido tres nociones afines que permiten comprender, cada una a su manera, el modo en que la creatividad se apoya en, y depende de, estructuras cognitivas y corporales introducidas en la socialización. Lo que tienen en común estas nocione s-las de tipo (Schütz y Luckmann, 2009: 224-235), marcos de la experiencia (Goffman,

9 Cf., para una síntesis breve pero completa, Castoriadis (1998b: 298-331). 
2006) y habitus (Bourdieu, 2007: 85-105) - es que describen la estructuración que la socialización impone a la imaginación, pero dan cuenta también, aunque de un modo indirecto10, del modo en que la imaginación de apoya en esas estructuras y puede desplegarse a partir de ellas.

El concepto de tipo, retomado por Schütz a partir de Husserl, va asociado al de "acervo social de conocimiento", con el que Schütz describió el conglomerado de saberes, presupuestos y recetas que orientan la acción en el mundo de la vida cotidiana. Ese acopio tiene muchos componentes pero en esencia consiste en un conjunto de tipificaciones que ordenan la experiencia y orientan la acción. Un tipo consiste en la abstracción de rasgos relevantes que permiten constituir un conjunto; se organiza pragmáticamente, pues son los problemas significativos los que definen qué cosa justifica la existencia de un tipo; tiene además un "anclaje biográfico", que da al tipo socialmente elaborado una forma y un contenido específico para cada agente. En su funcionamiento lo esencial es que el tipo opera como "sintesis pasiva", es decir, como una operación pre-predicativa de orden espontáneo; implican de este modo no sólo la identificación de una experiencia como correspondiente al tipo, sino también protensiones y retenciones automáticas (conexión con un pasado y un futuro asociado a la experiencia presente); los tipos, en este sentido, incluyen lo que Husserl y Schütz llaman "horizontes", vivencias que son esperables a partir de lo dado en la inmediatez. Todo este complejo fenomenológico es lo que ponemos en juego cuando decimos, por ejemplo, que lo que tenemos en frente es un perro, o un perro de tal raza, pero también lo que ponemos en movimiento cuando definimos nuestra propia identidad ("obrero") o cuando hablamos de "el Estado" o los "recursos renovables".

Al principio de nuestro análisis acudimos precisamente a Schütz para aclarar el concepto de creatividad, y dijimos que para él toda acción con sentido implicaba un proyecto. Todo proyecto, agregamos ahora, echa mano de las tipificaciones, lo que da el punto de apoyo para precisar de qué modo las tipificaciones se emplean en proyectos nuevos, es decir,

\footnotetext{
${ }^{10}$ Ninguna de las tres nociones fue pensada inicialmente para comprender la cuestión de la creatividad; más bien al contrario, el trasfondo de las tres es la interpretación de la recurrencia de las prácticas en sus contextos cotidianos. Hay en lo que sigue entonces una lectura especial, ajena a las intenciones de los autores pero compatible, a nuestro juicio, con el sentido básico de sus propuestas.
} 
en acciones creativas. Tres son las cuestiones que proponemos al respecto. Primero, la experiencia organizada y previsible que ofrecen los tipos tiene como trasfondo la existencia de lo atípico, que cuando ocurre obliga a la revisión. La "re-explicitación de horizontes" (Schütz y Luckmann, 2006: 30-35) del tipo afectado puede ser un acto creativo, si lo que hace es enriquecer con nuevos contenidos el tipo existente. Por ejemplo, quien ante las reuniones de 2001 espontáneamente había tipificado el fenómeno como "asamblea", introduce nuevos contenidos en las experiencias que son acordes a esa idea (nuevas maneras de formular propuestas, nuevas formas de tomar decisiones grupales). Segundo, la remisión de una experiencia a un tipo que habitualmente no le corresponde es una modalidad posible de creatividad, como es el caso de quien tipifica como "igual" a quien previamente tenía por "distinto" 11 . Tercero, existe la posibilidad de elaborar directamente nuevas tipificaciones, lo que también es una forma específica e importante de creatividad: "la facultad-escribe S. Langer-de reconocer una fórmula común en este cúmulo fortuito de cosas es lo que llamamos genio científico" (Langer, en Rodríguez Pascual, 2005: 26).

La noción de marco (frame) desarrollada por Goffman puede interpretarse como una ampliación y a la vez una aplicación del concepto de tipo, pues a lo que se refiere Goffman en esencia es a la tipificación de situaciones sociales de interacción en co-presencia. Cuando nos enfrentamos a una situación de interacción, según su análisis, respondemos siempre a la pregunta "qué está sucediendo", siendo el "marco", inicialmente, la respuesta que damos a la pregunta. De este modo, cuando enmarcamos ("esto es una asamblea barrial") damos sentido a una infinidad de sucesos puntuales que acontecen en ese contexto, ponemos en movimiento una red de presuposiciones (por ejemplo acerca de los comportamientos y de sus motivos), hacemos conjeturas sobre lo ocurrido antes y sobre lo que vendrá después, y establecemos límites espaciales y temporales referidos al comienzo y el final de la interacción. Todo esto ocurre de manera prereflexiva, en el

11 En las asambleas de 2001 se produjeron varios desplazamientos identitarios de este tipo, siendo el más conocido el que asoció la situación de los sectores medios afectados por la confiscación de ahorros bancarios con la situación de los desempleados estructurales. La consigna "piquete y cacerola, la lucha es una sola" expresó claramente ese desplazamiento (el "piquete" se había convertido en la forma habitual de protesta de los desempleados, dando lugar al movimiento denominado "piquetero"; el golpear cacerolas era la forma emergente de protesta de la clase media urbana). 
sentido de que aplicamos marcos con facilidad pero rara vez podemos explicar en detalle lo que hacemos. Un marco, por último, no es sólo algo que ocurre en la mente del observador, sino algo que estructura efectivamente las prácticas y la interacción. Los marcos funcionan precisamente porque hay coherencia entre la percepción y la organización efectiva de la actividad.

Las descripciones empíricas de Goffman ofrecen pistas concretas para explicar cómo esta actividad enmarcadora se vincula con la creatividad de la acción. Por empezar, retoma en términos de marcos el tema de la fantasía y los sueños diurnos que tratamos en el apartado anterior. Existen a su juicio una serie de fenómenos-la amenaza, el ritual, el engaño, la broma-que imitan de manera codificada, y a sabiendas de los participantes, formas primarias de interacción. Por ejemplo, cuando alguien amenaza con golpear retoma aspectos concretos de un golpe real (un movimiento de las manos) pero de un modo recodificado que permite su comprensión como amenaza. Goffman llama a estos fenómenos "cambios de clave" (Goffman, 2006: 46-47) e incluye entre ellos a las fantasías o el "soñar despierto", en donde la persona imagina libremente pero siempre a partir de una franja codificada de actividad. Así, por ejemplo, puedo imaginar situaciones de lo más diversas sobre la próxima clase que tengo que dictar, pero al hacerlo pongo siempre en juego las reglas y supuestos que definen al marco "clase".

Los marcos pueden además ser fabricados más que simplemente cambiados de clave. En este fenómeno no tenemos una copia recodificada sino la invención lisa y llana de algo que en la cultura del caso no existía. Goffman lo ilustra con las ficciones simples de la cultura de masas (humanoides, clarividencia) pero está claro que los ejemplos pueden ser más importantes y nuestra ilustración del comienzo lo demuestra. Las asambleas de 2001 tienen, como dice Fernández, algo de agrupamiento catártico, algo de foro de discusión o de movimiento de protesta, pero pueden considerarse como tales también un marco nuevo.

Hay además un aspecto de los marcos, que Goffman llama "fórmula rolpersona", de especial importancia para nuestro análisis. Retomando su trabajo clásico sobre la "distancia de rol" sostiene que cada marco implica una distribución de roles y que cada rol tiene grados distintos de permisividad respecto de la actuación. Así, en un marco de clase universitaria más o menos solemne se supone que tanto profesores 
como alumnos tienen un desempeño acotado y estricto que cumplir, aunque posiblemente sea más rígido en el caso del profesor que en el de los alumnos, y más en el caso de un tipo administrativo de alumno que de otro. El grado en que "la persona" (self) tenga derecho a manifestarse en su singularidad dentro de un marco es una clave para interpretar la creatividad posible en la ejecución de su rol.

Por último, hay varios aspectos del funcionamiento del marco que lo debilitan como proceso institucionalizado e implican resquicios para prácticas novedosas. Uno es el de los acontecimientos excluidos de un marco por irrelevantes, pero que mantienen un potencial perturbador. Todo marco selecciona hechos y fenómenos que le competen y que no, pero los que quedan fuera (la jarra de agua del disertante) pueden entrar en escena transformando la previsibilidad del curso de acción. Otro fenómeno es el de la ambigüedad de la situación respecto de los marcos existentes, que implica la duda de cómo encuadrarlos y el eventual error de encuadre, fenómenos todos que contribuyen a romper la inercia y la previsibilidad. Hay además fenómenos de ruptura de marcos, que consisten en que las anticipaciones que se derivan de un encuadre resultan frustradas, transformando la naturaleza de la situación.

El concepto de habitus de Bourdieu es suficientemente conocido por lo que podemos señalar directamente tres aspectos de su naturaleza que se vinculan con la creatividad de la acción. Bourdieu insistió, en primer término, en que el habitus no es una estructura rígida sino un principio "generativo", afirmación que debe entenderse en el sentido de que el esquema, la regla o la estructura que implica es una suerte de gramática que da lugar a infinidad de realizaciones posibles. El vínculo que existe entre habitus y prácticas es por lo tanto el mismo que existe entre regla y actualización, lo que implica que, aunque todas las realizaciones tengan en común la regla, pueden tener una diversidad que a priori es imposible de establecer. El habitus en este sentido implica la posibilidad de creatividad aunque, como hemos argumentado en otro lugar (Cristiano, 2011), su énfasis está puesto en lo común más que en lo diverso de las prácticas.

En su funcionamiento efectivo el habitus opera en relación a situaciones, de acuerdo con la fórmula "habitus + situación = prácticas". Puesto que la situación es percibida de acuerdo con los habitus, y puesto que tiene un carácter potencialmente contingente, es contingente también el contenido de las prácticas efectivas que un mismo agente 
puede producir. También en este punto Bourdieu puso el énfasis en la "orquestación sin director de orquesta" que implica habitualmente el "sentido práctico", en la reiteración de situaciones y en la coherencia de las situaciones con los ámbitos en que el habitus se ha constituido. Pero incluyó en sus análisis el fenómeno del "desajuste" entre habitus y situaciones, que rompe la espontaneidad de las respuestas y obliga a la innovación o la invención.

Por último existen campos, posiciones al interior de los campos, e incluso situaciones específicas de clase, en las que la creatividad es una exigencia de la posición que termina fijándose como habitus. La idea de "habitus creativos" fue planteada expresamente por Bourdieu y ofrece un concepto concreto para la comprensión de la creatividad de la acción, por ejemplo en el análisis de las "estrategias heréticas" que caracteriza a las posiciones subordinadas en los campos de producción cultural.

Este último punto señala un aspecto común a las tres nociones, que es su remisión a las condiciones concretas en que ocurre el proceso de socialización. Tipos, marcos y habitus hacen referencia a contenidos situados, ya sea por ser específicos de una cultura (tipos y marcos), ya por corresponder a posiciones estructurales de poder relativo (los campos y las posiciones de clase). La eventual creatividad de la acción queda con ellos anclada a condiciones sociales específicas, lo que abre un espacio de análisis que por supuesto las trasciende. Al mismo tiempo el análisis muestra la importancia de la idea de "crisis" en el análisis de la creatividad de la acción. Si bien no es posible fijar un vínculo general, todo parece indicar que la ruptura de las rutinas prereflexivas es un desencadenante habitual de proyectos de acción nuevos.

\section{El NIVEL DISCURSIVO: PENSAMIENTO NARRATIVO Y PROYECTOS NUEVOS}

Cuando un agente actúa conscientemente, elaborando con anterioridad de manera lúcida lo que va a hacer, pone en movimiento un singular proceso cognitivo que consiste en contarse a sí mismo proyectos posibles de acción. Por ejemplo, al planificar la forma en que ordenará una serie de compras y trámites, organiza mentalmente los pasos a seguir, los tiempos de cada uno o los eventuales imprevistos, tomándose a si mismo como destinatario de un relato. En estos simples actos 
mentales pone en movimiento lo que Jerome Bruner (2004; 2009) denominó "pensamiento narrativo", una modalidad cognitiva a su juicio distinta del pensamiento "lógico" o "científico paradigmático". La hipótesis que proponemos es que esta noción es un medio útil para aclarar la de "proyecto nuevo", y por ende la creatividad de la acción en su nivel consciente.

Dos son las características básicas del pensamiento narrativo: la secuencialidad y la verosimilitud. A diferencia del paradigmático el pensamiento narrativo es "sintagmático": ordena una serie de eventos en el tiempo y los conecta mediante reglas de experiencia que rara vez tienen la forma de deducciones lógicas. Así, una narración afirma cosas como las paritarias del Estado cerraron al alza porque es un año electoral o, más sencillamente, era fin de semana asi que había poco tránsito. En esas secuencias, además, cada acontecimiento adquiere sentido en función de la historia de la que forma parte: una acción se revela como acertada oerrónea, por ejemplo, sólo en el conjunto de la trama. Pero además, la regla de vericidad de una narración no es la verdad en sentido estricto, sino la verosimilitud. Aún si se trata de un historiador, que documenta rigurosamente los hechos, la confección de la narración requiere conexiones que sólo son verosímiles, aceptables por su "semejanza con la vida" (Bruner, 2004: 23), pero no enunciados verificables en sentido estricto.

Esta "epistemología ambigua del relato", como la llama Bruner, es el aspecto más general en que el pensamiento narrativo ilumina la creatividad de la acción. Pues, a diferencia del pensamiento lógico, el narrativo es un medio flexible para postular realidades imaginarias, cuyo vínculo con lo establecido como "real" puede ser más o menos directo, pero siempre apoyándose en la maleabilidad de lo verosímil. En otras palabras, en la medida en que lo verosímil es más abierto y difuso que lo verdadero, abre un cauce también más amplio a la imaginación creadora de mundos posibles.

Cómo en concreto lo hace es lo que permite dilucidar el análisis técnico de las narraciones. Así, Bruner propone la noción de "subjuntivización de la realidad" para designar las estrategias por las que un relato amplía el mundo corriente de manera creíble. Una de esas estrategias es el uso activo de las suposiciones: toda realidad humana tiene implícitos y supuestos, de los que la narrativa hace uso para convocar la actividad del destinatario, generar su sorpresa o su duda, o simplemente inducirlo 
a interpretar, suponer o hipostasiar. Otra estrategia es la apelación a la visión de la realidad filtrada por el punto de vista del actor, más que expuesta taxativamente por el narrador. En la misma línea la narración apela a la multiplicación de puntos de vista, lo que convierte a la realidad en un caleidoscopio de perspectivas parciales, difíciles de articular entre sí. Y un largo etcétera. Todas estas estrategias, que en los relatos de ficción forman la materia específicamente literaria, están presentes potencialmente según Bruner en todo pensamiento narrativo, de lo que se sigue que están presentes también en la auto-narración de proyectos de acción. La novedad de un proyecto, y por ende la creatividad de la acción, puede considerarse anclada en este tipo de estrategias y función de la intensidad con que las ponga en práctica.

Una segunda entrada la ofrece la estructura formal de las narraciones. Todo relato tiene como componentes mínimos a actores, a los que se supone dotados de identidad y de intenciones; el mundo en que los actores se mueven; expectativas sobre la condición habitual de ese mundo; una infracción a ese orden habitual, que es lo que desencadena la historia; las acciones que se ponen en movimiento a partir de esa alteración; y los resultados o el desenlace que se produce en consecuencia. En cada componente, en sus relaciones, y obviamente en el conjunto que forman, es posible situar la base de operaciones que aumentan el calado y la riqueza a la realidad tal como se percibe espontáneamente. Imputar, por ejemplo, identidades no convencionales a un actor, o dotar al entorno de la acción de características habitualmente no reconocidas, son medios concretos de los que se vale la formulación de proyectos creativos.

EI análisis literario sobre verosimilitud ${ }^{12}$ aporta muchas herramientas similares, orientadas globalmente a establecer de qué modo un relato consigue credibilidad como descripción de un mundo posible. Además del amplio ámbito de indagación que abren, estos trabajos recuerdan que la capacidad de los agentes para inventar planes de acción viene también influida por la reserva de historias de una cultura, por los mitos, leyendas y relatos de distinto tipo que forman parte del acervo sociocultural. Al proyectar conscientemente acciones no

12 Puede verse para una aproximación el número 11 de la revista Communications, dedicado íntegramente al tema y punta de lanza en su momento de una amplia discusión (http://www.persee.fr/web/revues/home/prescript/issue/comm_0588-

8018_1968_num_11_1). 
convencionales los agentes hacen uso de ese depósito, y de nuevo los acontecimientos de 2001 sirven como ilustración: ¿cuánto de las prácticas asamblearias viene inspirado-con todas las hibridaciones y transformaciones del caso-por las memorias narrativas de los participantes respecto de otros momentos y acontecimientos de la historia?

El pensamiento narrativo no es más que uno de los mecanismos lingüisticos que se activan en la creatividad consciente. Lo destacamos por su conexión con la idea de proyecto y desde allí con nuestra definición inicial de la "creatividad". Pero es obvio que la concepción del pensamiento como lenguaje abre otras muchas posibilidades, de las que son ilustraciones los trabajos de P. Ricoeur sobre la metáfora y los de M. Bajtín sobre las relaciones dialógicas ${ }^{13}$.

\section{HIPÓTESIS DE ARTICULACIÓN ENTRE NIVELES}

La formulación de hipótesis precisas de este tipo requeriría por supuesto un desarrollo más amplio de cada nivel. Sobre la base de lo dicho, sin embargo, se pueden realizar algunas indicaciones, para seguir las cuales ofrecemos el siguiente cuadro de síntesis sobre el argumento desarrollado hasta aquí:

13 Según Ricoeur, la noción de imaginación puede aclararse globalmente mediante la de metáfora, y el análisis lingüístico de ésta constituirse en medio de análisis de la imaginación en su conjunto (Ricoeur, 2000). Bajtín concibió el pensamiento como un diálogo interno, y a las relaciones dialógicas como un intercambio que no puede reducirse a relaciones lógicas ni sintácticas (Bajtín, 1995: 309). 
Conciencia/Autoconocimiento

$(+)$

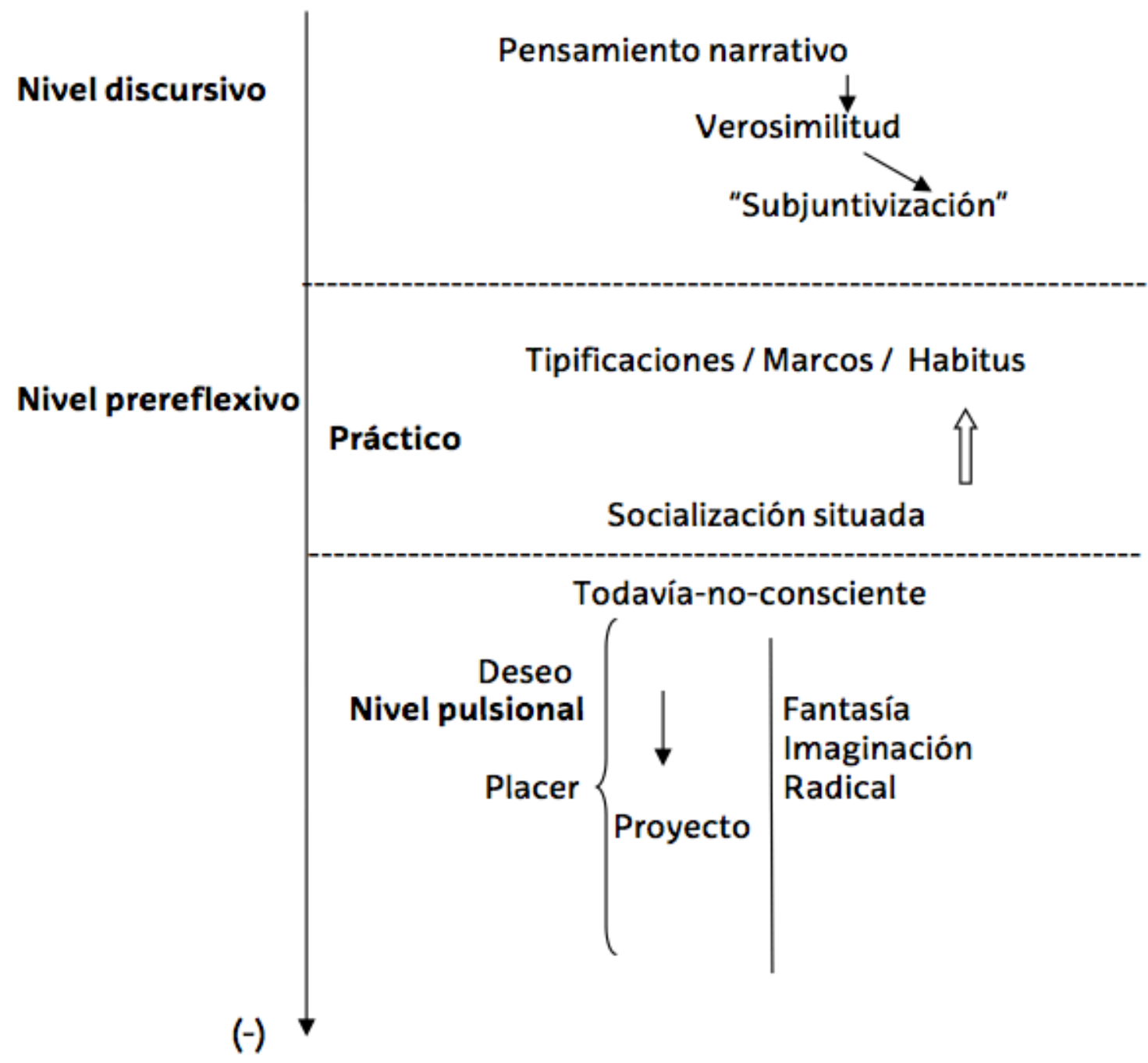

(i) La primera hipótesis surge de tomarse en serio una afirmación ocasional de P. Bourdieu, según la cual el interés ligado a los campos es una "libido social" (Bourdieu, en Gutiérrez, 2004: 47). Las nociones que tratamos en el nivel pre-reflexivo (habitus, tipo y marco) pueden considerarse en efecto como socialización de las pulsiones del primer nivel, lo que significa que cargan de contenido concreto, amén de sociológicamente relevante, la dinámica del placer y del deseo. 
(ii) En el mismo sentido puede decirse que las nociones del segundo nivel cargan de contenido al "principio de realidad". Ello significa que, en la medida en que la fantasía tenga un correlato "realista"-como insistía Bloch y como ilustra nuestro ejemplo de 2001-dependerá de la elaboración social de la factibilidad que describen categorias como habitus, marco y tipo.

(iii) Al presentar las ideas de Castoriadis dijimos que, por exitoso que sea un proceso de socialización, la psique conserva siempre una potencia instituyente que se deriva de su indeterminación en última instancia. En contrapeso de la afirmación anterior hay que decir por tanto que la imaginación radical de la psique, su carácter esencialmente indeterminado, y finalmente irreductible a la lógica identitaria, es una fuerza potencialmente capaz de erosionar la fijeza del nivel prereflexivo.

(iv) Freud describió a las fantasías diurnas como "guiones imaginarios" empleando en sus análisis muchos términos literarios o dramatúrgicos, como "novela" o "personaje". Ello indica una conexión precisa del nivel pulsional con el pensamiento narrativo de nuestro tercer nivel. La estructura y la lógica del pensamiento narrativo-ésta es la hipótesisdescribe, con más amplitud y detalle que los análisis freudianos, el aspecto de contenido de las fantasías diurnas, siendo compatible, en principio, con su explicación a nivel pulsional.

(v) El pensamiento narrativo se apoya en, y no puede desligarse de, las disposiciones sociales inscriptas en habitus, marcos y tipificaciones. Cuando un agente proyecta conscientemente cursos de acción no puede menos que poner en movimiento esos condicionamientos sociales de la experiencia que definen, entre otras cosas, lo que es esperable del mundo social, lo que en él es posible, el elenco de actores y situaciones relevantes, etcétera. En este sentido, las nociones del nivel pre-reflexivo son al nivel narrativo lo mismo que el acervo cultural de historias, mitos y leyendas: recursos, contenidos, ejemplos.

(vii) Si es cierto, no obstante, que el pensamiento narrativo tiene la capacidad de subjuntivizar la realidad, de mover los límites de lo corriente y de lo dado, hay que imputarle también una capacidad potencial para dinamizar y eventualmente desestructurar las disposiciones pre-reflexivas.

Un supuesto importante de estas sugerencias es que ninguno de los tres niveles puede considerarse a priori el más relevante. Por efecto de las 
especialidades es común por ejemplo que un psicoanalista tienda a sobrevalorar las pulsiones y los deseos, del mismo modo y por las mismas razones por las que los sociólogos damos más crédito al habitus que al subconsciente. La articulación de los tres niveles que puede avistarse en estas afirmaciones requiere una consideración equilibrada de la importancia de cada uno y la afirmación consecuente de que la creatividad de la acción depende, por lo menos a nivel abstracto, de los tres niveles por igual.

\section{PERSPECTIVAS DE DESARROLLO}

Hemos limitado nuestro análisis a una descripción teórica del agente social. Esto es sólo un aspecto de lo que podría llamarse una "sociología de la acción creativa", que tendría que incluir, como mínimo, una teoría de la acción (diferente formalmente de la teoría del agente), una teoría de la socialización (de qué modo el agente se constituye socialmente como tal), una teoría del vínculo entre acción y estructura social (qué conexiones sistemáticas existen entre condiciones estructurales, socialización y acción) y, por razones claras desde nuestro ejemplo inicial, también una teoría de la acción colectiva, entendiendo por tal la coordinación de acciones singulares bajo la órbita de proyectos "nuevos" elaborados colectivamente. Estos temas marcan una agenda de investigación para continuar lo que hemos planteado, pero también están detrás de las razones por las que hemos optado por unas herramientas teóricas en lugar de otras. Así, por ejemplo, el psicoanálisis es una amplia plataforma para investigar los temas de la socialización, pero también los de la acción colectiva; numerosos temas estructurales se perfilan detrás de las categorias de tipo, marco y habitus, pero también, en un sentido distinto, en el trasfondo cultural de historias y narraciones implicada en el pensamiento narrativo. En este sentido el esquema propuesto es potencialmente resistente para intentar también su proyección sobre estos ámbitos, aunque sin duda el todo y la parte deben acomodarse mutuamente. Finalmente, el hecho de que hayamos optado por elaborar un esquema teórico no prejuzga sobre el valor de la investigación empírica para respaldar o reorientar la propuesta. En la medida en que el esquema sea correcto (y subrayamos de nuevo que es sólo un esquema) más temprano o más tarde debería servir, con las mediaciones del caso, para aclarar también problemas empíricos. 
Una última consideración se refiere precisamente a la conexión del esquema con el ámbito empírico que pretende abarcar. Desde nuestra definición inicial queda claro que no hablamos exclusivamente de prácticas excepcionales como las que caracterizan al arte $o$ la inspiración científica o filosófica, pero tampoco reducimos la creatividad a una dimensión analítica de cualquier acción, a algo que podría ser identificado incluso en las prácticas más rutinarias. La creatividad es un destino posible de la acción social, algo que puede o no suceder, pero abarca un espectro de relevancias que va desde la creatividad micro de prácticas cotidianas hasta el gran acontecimiento creativo del arte o de la política. Nuestra hipótesis es que un mismo esquema general puede iluminar todo el espectro, pero a condición de avanzar en esa más amplia sociología de la acción creativa que acabamos de perfilar.

\section{BIBLIOGRAFÍA}

Bajtin, M., 1996, "El problema del texto en la lingüística, la filología y otras ciencias humanas. Ensayo de análisis filosófico", en M. Bajtin, Estética de la creación verbal, Siglo XXI, Madrid, pp. 294-273.

Bloch, E., 2004, El principio esperanza, Vol. 1, Trotta, Madrid.

Bourdieu, P., 2007, El sentido práctico, Siglo XXI, Buenos Aires.

Bruner, J., 2009, Actos de significado. Más allá de la revolución cognitiva, Alianza, Madrid.

Bruner, J., 2004, Realidad mental y mundos posibles. Los actos de la imaginación que dan sentido a nuestra experiencia, Gedisa, Barcelona.

Castoriadis, C., 1998a, "De la mónada a la autonomía", en C. Castoriadis, Hecho y por hacer. Pensar la imaginación, Eudeba, Buenos Aires, pp. 103-129.

Castoriadis, C., 1998b, "Imaginación, imaginario, reflexión", en C. Castoriadis, Hecho y por hacer. Pensar la imaginación, Eudeba, Buenos Aires, pp. 267-331.

Cristiano, J., 2010, "La creatividad de la acción: el modelo joasiano y la cuestión de lo imaginario", en Nómadas, Vol. 25, nº 1.

Cristiano, J., 2011, "Habitus e imaginación", en Revista Mexicana de Sociología, Vol. 73, $n^{\circ} 1$, pp. 47-72. 
Emirbayer, M., Mische, A., 1998, "What is agency", en American Journal of Sociology, Vol. 103, n³, pp. 962-1023.

Fernández, A. M. y colabs., 2006, Política y subjetividad. Asambleas barriales y fábricas recuperadas, Biblos, Buenos Aires.

Fiorini, H., 2006, El psiquismo creador. Teoría y clínica de los procesos terciarios, Nueva Visión, Buenos Aires.

Freud, S., 1979, "El creador literario y el fantaseo", en S. Freud, Obras Completas, Tomo IX, Amorrortu, Buenos Aires, pp. 125-135.

Freud, S., 1980, "Formulaciones sobre los dos principios del acaecer psíquico", en Obras Completas, Tomo XII; Amorrortu, Buenos Aires.

Giddens, A.,1995, La constitución de la sociedad. Bases para la teoría de la estructuración, Amorrortu, Buenos Aires.

Goffman, E., 2006, Frame Analisys. Los marcos de la experiencia, CIS, Madrid.

Gutiérrez, A., 2004, Las prácticas sociales. Una introducción a Pierre Bourdieu, Tierra de Nadie, Madrid.

Joas, H., 1998, El pragmatismo y la teoría de la sociedad, CIS, Madrid.

Joas, H., 2005, The Creative of Action, University of Chicago Press, Chicago.

Laplanche, J., 1999, La sublimación. Problemáticas III, Amorrortu, Buenos Aires.

Laplanche, J., Pontalis, J. B., 1996, Diccionario de Psicoanálisis, Paidos, Buenos Aires.

Laplanche, J., Pontalis, J. B., 2008, Fantasía originaria, fantasía de los origenes, origenes de la fantasía, Gedisa, Barcelona.

Lapoujade, M., 1988, Filosofía de la imaginación, Siglo XXI, México.

Parsons, T., 1968, Hacia una teoría general de la acción, Kapeluz, Buenos Aires.

Ricoeur, P., 2000, "La imaginación en el discurso y en la acción", en Del texto a la acción. Ensayos de hermenéutica II, FCE, Buenos Aires.

Rodríguez Pascual, E., 2005, El arco creativo. Aproximación a una teoría unificada de la creatividad, Ed. Universidad de Cantabria, Santander.

Schütz, A., 1972, Fenomenología del mundo social. Introducción a la sociología comprensiva, Paidos, Buenos Aires. 
Schütz, A., Luckmann, T., 2009, Las estructuras del mundo de la vida, Amorrortu, Buenos Aires.

Ungar, V., 2001, "Imaginación, fantasía y juego", Psicoanálisis APdeBA, Vol XXIII, $n^{\circ} 3$, pp. 695-711.

Warnock, M., 1981, La imaginación, FCE, México.

Weber, M., 1996, Economía y sociedad, FCE, México. 